\title{
Environmental Friendly Production of Amylase from Aspergillus niger EFRL-FC-024 Using Corn Waste as Carbon Source
}

\author{
Imrana Khushk ${ }^{1}$, Hiba Zahid ${ }^{1}$, Abdul Nabi Jatt ${ }^{2}$, Abdul Sattar Qureshi ${ }^{1}$, \\ Muhammad Aqeel Bhutto ${ }^{1}$ and Bushra Watoor ${ }^{1}$ \\ ${ }^{1}$ Institute of Biotechnology and Genetic Engineering, University of Sindh, Jamshoro (76080), Pakistan. \\ ${ }^{2}$ Institute of Microbiology, University of Sindh, Jamshoro (76080), Pakistan. \\ *Corresponding Author Email: abdul.nabi@usindh.edu.pk \\ Received 12 September 2020, Revised 04 December 2020, Accepted 09 April 2021
}

\begin{abstract}
Amylase is an indispensable and industrially important enzyme that hydrolyzes carbohydrates particularly starch into simple sugars. Amylase enzymes have been isolated from various sources such as microbes, animals and plants. However, microorganisms are highly preferred as compared to plants and animal sources. Amylases of fungal origin are highly stable compared to amylases produced by bacterial species. The aim of this study was to investigate the production of extracellular amylase enzyme from Aspergillus niger EFRL-FC-024 using sugarcane bagasse and corn waste as an energy source under submerge fermentation conditions. Primarily, the fungal strain was grown for 6 days using sugarcane bagasse and corn waste, respectively. Mainly, the growth of a microorganism was also evaluated using different $\mathrm{pH}$, temperature and incubation periods. The results revealed maximum amylase production of $1.64 \mathrm{U} / \mathrm{mL}$ when A. niger was cultured for $96 \mathrm{~h}$ using corn waste. Moreover, addition of different nitrogen sources showed the highest amylase production when peptone was supplemented as a nitrogen source. Finally, the effect of $\mathrm{pH}$ indicated maximal concentration of amylase enzyme at $\mathrm{pH}$ 6.0. The present study will highly be beneficial to explore the role of fungal strain A. niger in amylase production at Industrial levels.
\end{abstract}

Keywords: Amylase, Corn waste, Peptone, Aspergillus niger EFRL-FC-024.

\section{Introduction}

Amylase enzymes are of great importance in the hydrolysis of starch into different forms such as dextrin, maltose and glucose units [1]. Amylase enzymes have broad applications in industries for the processing of food, fermentation and pharmaceutical substances. Amylase enzymes have been isolated from various sources such as microbes, animals and plants. However, microorganisms are highly preferred compared to plants and animal sources due to low cost, fast growth, thermal stability and safe use [2]. Amylases have a great value for biotechnology having a world enzyme market of approximately 30\% [3]. The amylolytic enzymes are divided into $\alpha, \beta$ and $\gamma$ subtypes. Among these subtypes, $\alpha$ and $\beta$ amylases are considered as the highly important amylases widely isolated from microbial sources [4]. Mainly, $\alpha$-amylase enzymes are highly active subtypes as compared to $\beta$ amylases. Amylases are also called glycoside hydrolases as they act on $\alpha-1$ 4 glycoside bonds [4]. These enzymes can also be classified into endo and exo-amylases. The endo-amylases perform hydrolysis of amylose molecules into short linear and 
branched oligosaccharides chains of variable length. Exo-amylases catalyze the hydrolysis of a substrate using non-reducing endpoint and resulting in shorter end products [5].

Generally, starch is a major nutrient source of the human diet and is found as a storage product in various crops, e.g., rice, maize, potato and wheat. Starch hydrolyzing enzymes are mostly used in the preparation of glucose and fructose syrups [6]. Structurally, starch is composed of amylose and amylopectin glucose polymers. Amylose is made up of approximately 6000 units of glucose molecules attached by $\alpha-1-4$ glycosidic bonds and amylopectin is made up of 10-16 units of glucose molecules attached with $\alpha-1-4$ glycosidic bonds along with side chains of 15-16 units of glucose units linked by $\alpha-1-6$ glycosidic bonds [4]. Many types of microorganisms have been shown to produce amylases, however, only some of these are confirmed as the most industrially important microbes with a high yield of amylase production, such as Aspergillus niger, Bacillus amiloliquefaciens and Bacillus licheniformis [7]. Predominantly, fungal amylase enzymes are utilized for industrial productions at a large scale due to various advantages, i.e., easy and simple fermentation process, consistency, simple optimization process and cost effectiveness [5]. Some fungi of genus Penicillium and Aspergillus play an important role in the production of industrially important extracellular enzymes and other substances such as amylase, lipase, pectinase and cellulase, tartaric acid, citric acid and gluconic macromolecules [6]. However, fungal species belong to the genus Aspergillus such as $A$. niger, A. kawachii, A. oryzae and A. awamori are extensively used for the production of extracellular amylases. Moreover, A. niger has been found as a highly effective microbial source to produce industrially important amylases and other extracellular enzymes, including citric acid [8]. A. niger is a haploid filamentous fungal species also used for biotransformation and waste management.

Amylase production can be achieved using different agro-industrial residues as carbon sources such as corn straw, rice straw, wheat straw and rice husk and these all residues are generally known as cost effective carbon sources. Waste materials utilized for amylase production may play a vital role in the solution of environmental pollution problems [1]. Enzymes particularly isolated from the microbial source have great importance world-wide due to a wide range of applications in various industrial sectors such as paper, food, detergent and food industries. Microorganisms as a source for the production of enzymes is a preferred choice for researchers due to the ease of genetic manipulation and broad biochemical diversity [9]. Hence, still researchers are in search for novel microbial strains characterized with maximal production of extracellular enzymes [1]. As the composition of media strongly influences growth and enzyme production, optimizing the media components and the cultural parameters are essential in standardizing a bioprocess [10]. This is why, in the present study, amylase production using corn waste has been optimized to achieve the highest possible amylase concentration.

This study has been carried out to investigate the production of extracellular amylase enzyme from $A$. niger using sugarcane bagasse and corn waste as substrate under submerge fermentation conditions.

\section{Materials and Methods Chemicals}

The chemicals used in this study, such as peptone, casein, tryptophan and yeast extract, meat extract, ammonium chloride and ammonium sulphate were purchased from Merck. While potassium sodium tartrate, 
sodium hydroxide and 3,5-dinitrosalicylic acid were from Sigma-Aldrich. All the chemicals were used and prepared for experimental work as per manufacturers' instructions.

\section{Microorganism}

Aspergillus niger EFRL-FC-024 was available in our laboratory and stored at $4{ }^{\circ} \mathrm{C}$ on agar slants. The fungal culture was activated by growing on glucose agar slants. This strain was used for amylase production. Activation media was composed of $20 \mathrm{~g} / \mathrm{L}$ glucose, $10 \mathrm{~g} / \mathrm{L}$ of peptone and $20 \mathrm{~g} / \mathrm{L}$ of agar as a solidifying agent.

\section{Fermentation media and Cultivation Conditions}

Fermentation media was prepared by using the following components containing sugarcane bagasse $20 \mathrm{~g} / \mathrm{L}$ or corn waste powder $20 \mathrm{~g} / \mathrm{L}$ as a carbon source and $\mathrm{KH}_{2} \mathrm{PO}_{4} 2.0 \mathrm{~g} / \mathrm{L}$, peptone $10 \mathrm{~g} / \mathrm{L}$ and $\mathrm{MgSO}_{4}$ $2.0 \mathrm{~g} / \mathrm{L}$. Control was prepared by using glucose $20 \mathrm{~g} / \mathrm{L}$ in place of sugarcane bagasse or corn waste. All the fermentation media flasks were autoclaved for sterilization at 121 ${ }^{\circ} \mathrm{C}$ for $15 \mathrm{~min}$. Suspension of Aspergillus niger $(2.0 \% \mathrm{v} / \mathrm{v})$ was used to inoculate media. All the inoculated media were incubated for 6 days [11]. Samples from the media were collected at a regular interval of $24 \mathrm{~h}$ and were analyzed for amylase production. The broth was stored in a refrigerator for biochemical analysis. All experiments were performed in triplicate.

\section{Effect of nitrogen source on the production of amylase enzyme}

Various kinds of nitrogen sources such as peptone, casein, tryptophan and yeast extract, meat extract, ammonium chloride and ammonium sulphate were added to fermentation media in order to evaluate the influence of each nitrogen source on amylase production, respectively. Mainly, corn waste $20 \mathrm{~g} / \mathrm{L}$ (optimized carbon source) was used as a carbon source. All experiments were performed in triplicate.

\section{Effect of $\mathrm{pH}$ on the production of amylase enzyme}

Effect of $\mathrm{pH}$ on amylase production was observed by adjusting fermentation media with $\mathrm{pH}$ ranges from 5 to 10 [7]. Optimized fermentation conditions with corn waste (20 $\mathrm{g} / \mathrm{L})$ and peptone $(10 \mathrm{~g} / \mathrm{L})$ were supplemented as carbon as well as nitrogen sources and the reaction was incubated for $96 \mathrm{~h}$.

\section{Determination of Amylase Activity}

Amylase activity was determined as described by Keharom et al., [12]. Principally, a substrate of $1.0 \mathrm{~mL}$ was mixed with a culture broth of $1.0 \mathrm{~mL}$. Blank was prepared by replacing substrate with water and processed as accordingly. Subsequently, the mixture was incubated for $15 \mathrm{~min}$ at $37{ }^{0} \mathrm{C}$ followed by the addition of dinitro salicylic acid (DNS) (2.0 mL) in each tube, respectively. The addition of DNS was to stop the reaction and color production. The reaction mixture in all the test tubes was placed in a boiling water bath for $5 \mathrm{~min}$. Finally, all the test tubes were cooled at room temperature and the amylase production was confirmed using a spectrophotometer at a wavelength of $540 \mathrm{~nm}$ against the blank solution. Whereas one unit of amylase production was defined as the concentration of enzyme required for the liberation of $1.0 \mu \mathrm{M}$ of the reducing sugars.

\section{Results and Discussion}

Carbon and nitrogen sources have a great value in the production of microbial extracellular enzymes and other important 
polysaccharides. Several carbon sources have been reported to be used to produce enzymes [3-8]. Fig. 1 shows the comparative study of amylase production from Aspergillus niger EFRL-FC-024 when different materials were used as carbon sources (sugarcane bagasse, corn waste and glucose) under submerged fermentation conditions. The results showed the maximum production of amylase after 48 $\mathrm{h}$ using corn waste as a substrate in comparison to sugarcane bagasse and glucose. Amylase concentration reached to $4.48 \mathrm{U} / \mathrm{mL}$ when corn waste was used as substrate. Several carbon sources such as corn, tapioca, starch and potato have widely been used in submerged fermentation for extracellular amylase production [3-9-13]. Sidkey et al., [9] reported corn gluten as the best carbon as well as a nitrogen source for amylase production. Predominantly, extracellular amylases are of great importance and have been used for the degradation of polysaccharides at a large scale by food industries [11]. However, the selection of a specific potential substrate is of great concern in the production of amylases. Mainly, substrate selection for the production of extracellular enzymes is based on various factors bound with the availability and cost of the substrate [9]. Agro-industrial wastes used in this study, such as corn waste and sugarcane bagasse are the cheapest and easily available carbon sources. Principally, physical and chemical parameters in optimal conditions for the fermentation process are highly significant in the production of biologically active substances from microorganisms [9]. B. subtilis was inoculated into the solid residues such as wheat bran, banana peel, orange peel, rice bran and pineapple peel. Among the tested solid wastes, wheat bran enhanced the production of amylase $(640 \mathrm{U} / \mathrm{g})$ than other tested substrates. Also, the other substrates such as rice bran and orange peel, banana peel and pineapple peel supported amylase production [14].

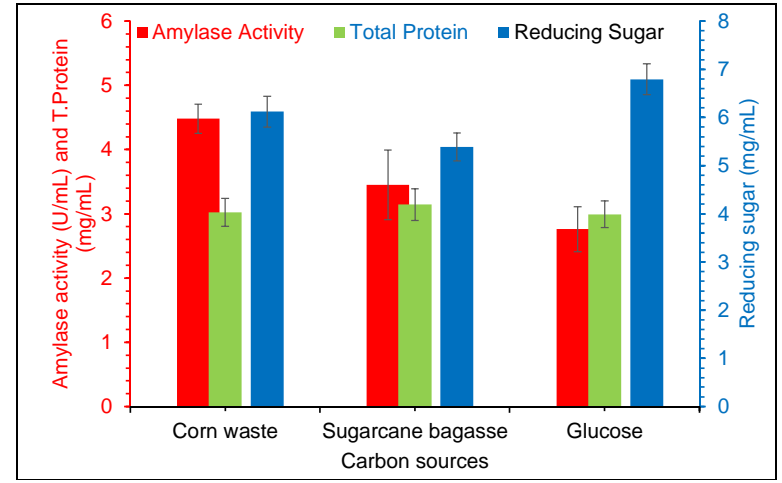

Figure 1. Comparison of amylase production from Aspergillus niger EFRL-FC-024 using different sugars

Generally, various factors such as substrate, $\mathrm{pH}$, temperature and incubation period may influence the production of amylases depending on microbial species origin [8]. Fig. 2. shows the influence of fermentation time the production of extracellular amylases when corn waste was used as a carbon source. Amylase activity increased with fermentation time and maximal amylase activity of $6.95 \mathrm{U} / \mathrm{mL}$ was noted after $96 \mathrm{~h}$ of incubation. On further increasing the fermentation time, the enzyme activity decreased probably due to inhibition of microbial growth or accumulation of waste products [15]. Amylase enzyme produced by $A$. niger and $R$. stolonifer fungi increased with the length of the incubation period, with a maximum after 6 days; further incubation decreased enzyme production [16].

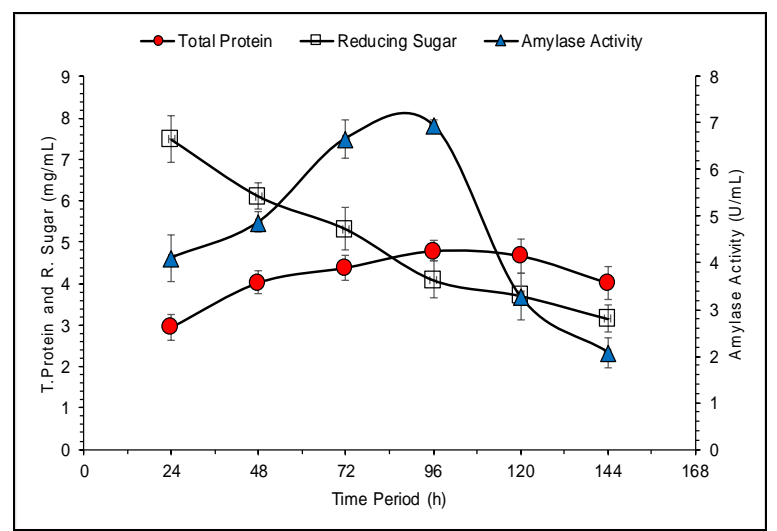

Figure 2. Batch profile of amylase production using corn waste as carbon source from Aspergillus niger EFRL-FC-024 
Figure 3. indicates the influence of organic and inorganic sources on the production of amylase enzyme. Highest amylase concentration was noted when peptone was used as a nitrogen source in a mineral medium containing corn waste as a carbon source. Most of the microorganisms grow better and produce desired products with organic nitrogen sources. In view of previous studies, different nitrogen sources, i.e., yeast extract, sodium nitrate, ammonium nitrate, casamino acids and peptone were shown to stimulate the highest amylases production in fungal species [9,17-18]. Peptone and yeast extract or beef extract are highly preferred in the highest yields of $\alpha$-amylases [19-21]. Accordingly, the present study has also revealed peptone as the best nitrogen source, which stimulated the highest production of extracellular amylase by A. niger EFRL-FC024. The amylase activity of KIIT BE-1 was maximal with yeast extract compared to various other organic and inorganic nitrogen sources. Though organic sources such as tryptone, beef extract and peptone showed a similar trend, inorganic nitrogen sources affected the production negatively [22]. Mitsunaga et al., [23] reported better amylase production with inorganic nitrogen sources by some bacterial species, possibly due to ecological reasons. For instance, microbes from the arid regions reportedly prefer inorganic nitrogen sources for amylase production.

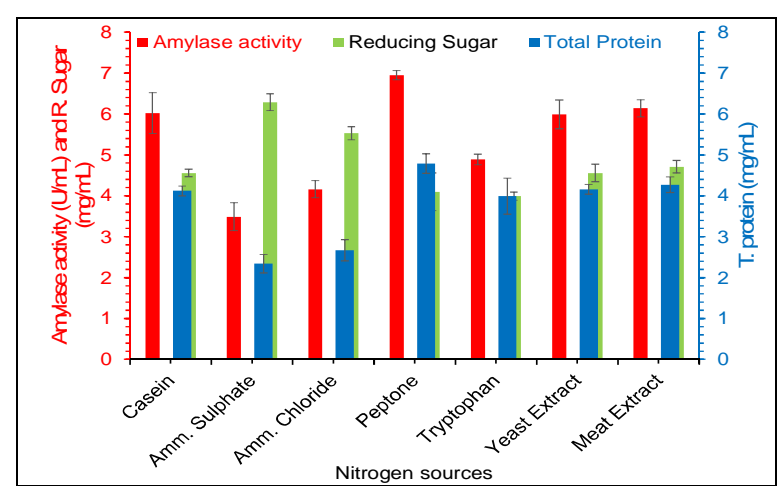

Figure 3. Influence of various sources on amylase production from Aspergillus niger EFRL-FC-024
In general, $\mathrm{pH}$ values critically influence enzyme activity, hence optimization of $\mathrm{pH}$ values is very important to obtain maximum enzymatic activities. Fig. 4 shows the effect of initial $\mathrm{pH}$ on amylase production. Amylase production was studied in the $\mathrm{pH}$ range of 5-10, enzyme activity increased with $\mathrm{pH}$ up to 6 then decreased. This might be due to $\mathrm{pH}$ dependent regulation of gene expression. Literature has reported similar findings [12]. Dar et al., [24] investigated the production of extracellular amylase from Penicillium chrysogenum and maximal concentration was noted at $\mathrm{pH} 6$. In contrast to, Simair et al., [25] have reported amylase production from Bacillus sp. in alkaline $\mathrm{pH}$ ranges. The highest production of amylase by the two fungi was in a culture medium initially adjusted to $\mathrm{pH}$ 6. Considerable amounts were also recorded at $\mathrm{pH} \mathrm{5,7}$ and 8 but low levels in more acidic or alkaline cultures [16].

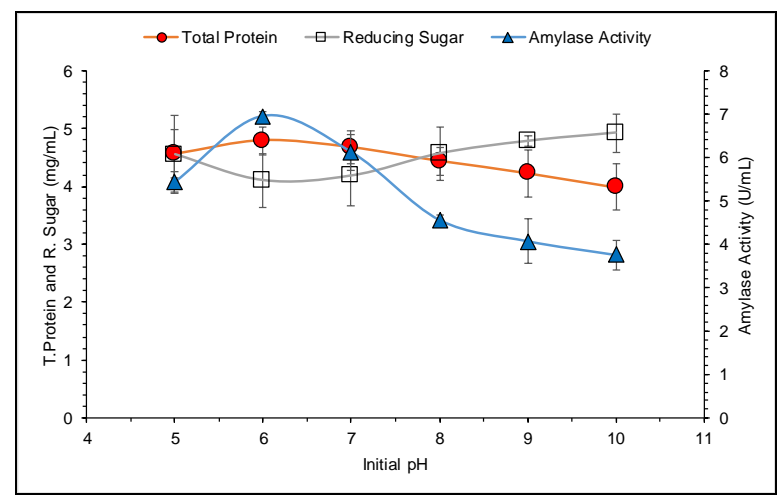

Figure 4. Influence of initial $\mathrm{pH}$ on amylase production from corn waste

\section{Conclusion}

The present study has shown the production of extracellular amylase enzyme by Aspergillus niger in fermentation media supplemented with various carbon sources. The fungal strain was grown for 6 days using sugarcane bagasse and corn waste, respectively. Mainly, growth of a microorganism was also evaluated using 
different parameters such as $\mathrm{pH}$, temperature and incubation time. The results revealed the maximum amylase production $(1.64 \mathrm{U} / \mathrm{mL})$ when the microbial strain was cultured for 96 $\mathrm{h}$ at $28{ }^{\circ} \mathrm{C}$ using corn waste. Moreover, the effect of various nitrogen sources on amylase production showed the highest amylase activity when peptone was supplemented as a nitrogen source. Finally, the influence of $\mathrm{pH}$ on the production of amylase enzyme indicated maximal amylase concentration at $\mathrm{pH}$ 6. The present study will highly be beneficial to explore the role of fungal strain A. niger for extracellular amylase production at the industrial level.

\section{Acknowledgement}

We are thankful to the Institute of Biotechnology, University of Sindh, Jamshoro, for providing a laboratory facility to carry out this research work.

\section{Conflict of Interest} declare.

There is no conflict of interest to

\section{References}

1. A. A. Simair, A. S. Qureshi, I. Khushk, C. H. Ali, S. Lashari, M. A. Bhutto, G. S. Mangrio and C. Lu, BioMed. Res. Inter., 2017 (2017) 1-9. doi: 10.1155/2017/9173040.

2. M. F. Martin, E. A. Okpo and I. E. Andy, World News Natural Sci., 23 (2019) 13-23.

3. K. Ahmed, E. E. Valeem and Q. U. Haq, FUUAST J. Biol., 4 (2014) 205. https://fuuastjb.org/index.php/fuuastjb/ar ticle/view/170

4. S. C. Gopinath, P. Anbu, M. K. Arshad, T. Lakshmipriya, C. H. Voon, U. Hashim and S. V. Chinni, BioMed. Res. Inter., 2017 (2017) 9. https://doi.org/10.1155/2017/1272193
5. O. P. Magalhães and M. P. Souza, Braz. J. Microbiol., 41 (2010) 850. doi:10.1590/S1517-83822010000400004

6. G. H. Dar, A. N. Kamili, R. Nazir, S. A. Bandh and T. A. Malik, Int. J. Biotech. Mol. Biol. Res., 5(4) (2014) 35-40. https://doi.org/10.5897/IJBMBR2014.01 $\underline{96}$

7. R. Vidyalakshmi, R. Paranthaman and J. Indhumathi, World J. Chem., 4 (2009) 89. https://www.idosi.org/wjc/4(1)09/14.pdf

8. A. Gupta, V. K. Gupta, D. R. Modi and L. P. Yadava, Biotechnology, 7 (2008) 551. doi:10.3923/biotech.2008.551.556

9. N. M. Sidkey, M. Abo-Shadi, A. M. AlMutrafy, S. Fatma and N. Al-Reheily, J. Am. Sci., 6 (2010) 926. Corpus

ID: 212576262

10. K. N. Rajput, K. C. Patel and U. B. Trivedi, Biotechnol. Res. Int., 2016 (2016) 7. http://dx.doi.org/10.1155/2016/3584807.

11. S. Alva, J. Anupama, J. Savla, Y. Y. Chiu, P. Vyshali, M. Shruti, B. S. Yogeetha, D. Bhavya, J. Purvi, K. Ruchi, B. S., Kumudini and K. N. Varalakshmi, Afr. J. Biotechnol., 6 (2007) 576.

https://doi.org/10.5897/AJB2007.000$\underline{2050}$

12. S. Keharom, R. Mahachai, and S. Chanthai, Inter. Food Res. J., 23 (2016) 10-17.

https://www.cabdirect.org/cabdirect/abst ract/20163008767

13. B. A. Mahdi, A. Bhattacharya and A. Gupta, J. Chem. Technol. Biotechnol., 87 (2012) 418. https://doi.org/10.1002/jctb.2740.

14. T. N. Almanaa, P. Vijayaraghavan, N. S. Alharbi, S. Kadaikunnan, J. M. Khaled and S. A. Alyahya. J. King Saud Univ. Sci., 32 (2020) 1555. https://doi.org/10.1016/j.jksus.2019.12.011 
15. S. Kulshrestha, J. Pharmacy Res., 7 (2013) 792. https://doi.org/10.1016/j.jopr.2013.07.014

16. A. Saleem and K. Ebrahim, Saudi Arabia. J. Taibah Univ. Sci., 8 (2014) 90.

http://dx.doi.org/10.1016/j.jtusci.2013.09 .002

17. E. Nahas and M. M. Waldemarin, Revista Rev. Latinoam Microbiol., 44 (2002) 5.

PMID: 17061508

18. S. Shafique, R. Bajwa and S. Shafique, Microbiology, 79 (3) (2010) 287. https://doi.org/10.1134/S002626171003 $\underline{0021}$

19. L. M. Hamilton, C. T. Kelly and W. M. Fogarty, Process Biochem., 35 (1999) 27.

https://doi.org/10.1016/S00329592(99)00028-X

20. S. Hayashida, Y. Teramoto and T. Inoue, Appl. Environ. Microbiol., 54 (1988) 1516.

Doi: 0099-2240/88/061516-07\$02.00/0
21. R. Kammoun, B. Naili and S. Bejar, Biores. Technol., 99 (2008) 5602. https://doi.org/10.1016/j.biortech.2007.1 0.045

22. D. Raul, T. Biswas, S. Mukhopadhyay, S. Kumar Das and S. Gupta. Biochem. Res. Inter., 2014(2014) 5.

https://doi.org/10.1155/2014/568141

23. H. Mitsunaga, L. Meissner, T. Palmen, T. Bamba, J. Büchs and E. Fukusaki, J. Biosci. Bioeng., 121 (2016) 413. DOI: 10.1016/j.jbiosc.2015.08.012

24. G. H. Dar, A. N. Kamili, R. Nazir, S. A. Bandh, T. R. Jan and M. Z. Chishti, Microb. Pathog., $88 \quad$ (2015) 10. https://doi.org/10.1016/j.micpath.2015.0 7.016

25. A. A. Simair, I. Khushk, A. S. Qureshi, M. A. Bhutto, H. A. Chaudhry, K. A. Ansari and C. Lu, Fermentation, 3 (2017) 25.

https://doi.org/10.3390/fermentation302 $\underline{0025}$ 